\title{
A prospective randomised controlled trial of octylcyanoacrylate tissue adhesive and standard suture for wound closure following breast surgery
}

\author{
Clement TH Chen *, Catherine LY Choi, Dacita TK Suen, Ava Kwong *
}

This article was published on $22 \mathrm{Apr}$ 2016 at www.hkmj.org.

\section{A B S T R A C T}

Introduction: Several studies have demonstrated that octylcyanoacrylate tissue adhesive provides an equivalent cosmetic outcome as standard suture for wound closure. This study aimed to compare octylcyanoacrylate tissue adhesive with standard suture for wound closure following breast surgery.

Methods: A prospective randomised controlled trial was conducted in a public hospital in Hong Kong. A total of 70 female patients, who underwent elective excision of clinically benign breast lump between February 2009 and November 2011, were randomised to have wound closure using either octylcyanoacrylate tissue adhesive or standard wound suture following breast surgery. Wound complications and cosmetic outcome were measured.

Results: Octylcyanoacrylate tissue adhesive achieved wound closure in significantly less time than standard suturing (mean, 80.6 seconds vs 344.6 seconds; $\mathrm{P}<0.001)$. There was no statistical difference in wound condition or cosmetic outcome although number of clinic visits, ease of self-showering, and comfort of dressing significantly favoured octylcyanoacrylate tissue adhesive.

Conclusions: Octylcyanoacrylate tissue adhesive may be offered as an option for wound closure following breast surgery.

\section{Hong Kong Med J 2016;22:216-22}

DOI: $10.12809 / \mathrm{hkmj} 154513$

${ }^{1}$ CTH Chen *, FCSHK, FHKAM (Surgery)

${ }^{2}$ CLY Choi, FCSHK, FHKAM (Surgery)

'DTK Suen, FCSHK, FHKAM (Surgery)

${ }^{1}$ A Kwong *, FCSHK, FHKAM (Surgery)

1 Department of Surgery, Queen Mary Hospital and Tung Wah Hospital,

Hong Kong

2 Private practice, Hong Kong

* Corresponding authors: chenthc@ha.org.hk, avakwong@hku.hk

New knowledge added by this stud

- Use of octylcyanoacrylate (OCA) tissue adhesive in wound closure following breast surgery is feasible.

Implications for clinical practice or policy

OCA may be offered as an option for wound closure following breast surgery.

\section{Introduction}

In Hong Kong, thousands of patients undergo breast surgery every year for both benign and malignant conditions. $^{1}$ Patients expect a good cosmetic outcome and satisfactory postoperative wound management. This is in addition to the expectation of a cure, or in the case of breast cancer, complete removal of lesions with optimal survival.

Several studies have demonstrated that octylcyanoacrylate (OCA) tissue adhesive provides an equivalent cosmetic outcome to wound suturing in repair of lacerations, ${ }^{2,3}$ head and neck surgery, ${ }^{4}$ plastic surgery, ${ }^{5}$ and breast surgery. ${ }^{6,7}$ The OCA tissue adhesives are supplied as monomers in a liquid form. They polymerise on contact with tissue anions, forming a strong bond that holds the opposed wound edges together. The OCA tissue adhesive usually sloughs off with time. The wound epithelises within 5 to 10 days and the adhesive does not require removal.

In-vitro studies have shown that OCA provides an effective antimicrobial barrier for the first 72 hours after application. ${ }^{8}$ It is approved by the US Food and Drug Administration as a topical skin adhesive that protects the wound from bacteria. It also facilitates postoperative wound care as patients are allowed to shower immediately. There is no need for suturing, staple removal, or dressings. Higher patient satisfaction following skin closure with OCA tissue adhesive compared with sutures has been observed. ${ }^{6}$ Studies also show faster wound closure with OCA. ${ }^{9}$

This study aimed to assess the outcome of elective breast surgical incision repair with OCA tissue adhesive compared with standard wound suture (SWS). We compared the cosmetic outcome, complication rates, and patient satisfaction score for breast incisions in elective surgery closed with OCA tissue adhesive versus SWS. 


\section{Methods}

The study was in compliance with the Declaration of Helsinki and ICH-GCP (International Conference on Harmonisation, Good Clinical Practice). It was reviewed and approved by the institutional review boards.

Based on a randomised trial of OCA versus SWS in breast surgery, ${ }^{5}$ patient satisfaction in an OCA group has been reported to be significantly higher than that of a SWS group. To detect a difference with a power of $90 \%$ and $\alpha=0.05,35$ patients were needed for each arm.

A total of 70 female patients, who underwent elective excision of clinically benign breast lump between February 2009 and November 2011 in this randomised controlled trial, were randomly allocated to have wound closure using either OCA or SWS with a continuous monofilament subcuticular method. They were seen on the morning of the surgery, consented, and randomly allocated to a study arm. Each randomisation number was computergenerated, sealed in an envelope, and kept in a secure designated place. At the time of wound closure, the surgeon would call a third-party nurse to open the sealed envelope that would determine the method to be used for wound closure. The surgery was performed by specialists or surgical trainees under a specialist's supervision. Two evaluation forms were administered to collect information on wound condition and cosmetic grading by different parties.

Postoperatively, the wound condition was examined by a surgeon who was not involved in the study. An evaluation form was completed to note any indication of (1) wound infection, (2) dehiscence, (3) oozing, and (4) discharge on day 0-1 (early postoperative period) and day 10-14 (first followup).

The cosmetic grading of the surgical wound was checked on day 30 and 180 by an evaluator (surgeons not involved in the study or the above evaluations) who looked for any sign of (1) stepoff borders (edges not on same plane), (2) contour irregularities (wrinkled skin near wound), (3) margin separation (gap between sides), (4) edge inversion (wound not properly everted), and (5) excessive distortion (swelling/oedema/infection); and (6) evaluated the overall appearance of the wound.

Patient evaluation of whether the appearance of the wound was "good" or "bad" over a score of 1 (very bad) to 10 (very good) on day 30 and day 180 was also recorded.

Patients were also asked five questions about self-care of the wound at the day-30 visit. Questions were answered and rated on a 5 -point Likert scale (very good, good, neutral, bad, very bad) regarding (1) pain, (2) ease of caring, (3) self-showering, (4) frequency of hospital/clinic visits for wound cleansing, and (5) comfort level of wound dressing.
乳房手術後使用氭基丙烯酸辛酯 (octylcyanoacrylate) 組織粘合劑和標準縫合方 法治理傷口閉合的前瞻性隨機對照研究

陳梓欣、蔡麗賢、孫杜琪、廣靄慧

引言：研究顯示氰基丙烯酸辛酯組織粘合劑用於傷口閉合的效果可媲 美傳統的縫合術。本研究比較進行乳房手術後使用氧基丙烯酸辛酯組 織粘合劑與標準的縫合方法治理傷口閉合的效果。

方法：於香港一家公立醫院進行前瞻性隨機對照研究。共70名於2009 年 2 月至 2011 年 11 月期間接受良性乳房腫塊切除的女性患者, 被隨機 分配到以下其中一組進行傷口閉合: 氧基丙烯酸辛酯組織粘合劑以及 傳統的縫合方法, 並測量傷口併發症和美容效果。

結果：與傳統的縫合方法比較, 使用氭基丙烯酸辛酯組織粘合劑的一 組所需時間明顯較短（平均時間：粘合劑組80.6秒比傳統縫合組344.6 秒； $\mathrm{P}<0.001)$ 。兩組之間的傷口情況和美容效果均無顯著差異, 但 使用氭基丙烯酸辛酯組織粘合劑的一組在就診次數、淋浴的容易程度 和傷口敷料的舒適程度明顯較佳。

結論：氭基丙烯酸辛酯組織粘合劑可為乳房手術後的傷口閉合提供另 一個選擇。

\section{Statistical analyses}

Data were summarised with descriptive statistics. Means and standard deviations (for numeric variables) and numbers and percentages (for categorical variables) were calculated where appropriate. We checked the normality of the data and found that it did not follow the normal distribution. Therefore the Wilcoxon rank sum test and Fisher's exact test were applied to determine any significant difference between the OCA and SWS groups. All statistical analyses were done using the Statistical Package for the Social Sciences (Windows version 16.0; SPSS Inc, Chicago [IL], US) and $\mathrm{R}$ version 3.0.2 (the R Foundation). All statistical tests were two-sided and statistical significance was considered at $\mathrm{P}<0.05$.

\section{Results}

A total of 70 patients, half of whom were randomised to receive OCA or SWS, were entered into this study. One patient from the suture group was lost to follow-up and excluded from subsequent analysis, leaving a total number of 69 patients (35 for OCA group and 34 for SWS group).

\section{Demographic characteristics}

The demographics of the two groups were comparable. There was no statistical difference in terms of age, tumour size, co-morbidity including diabetes, pathology, laterality and location of the lesion, or the rank of the surgeon involved (Table 1). 
TABLE I. Surgical and demographic characteristics of study participants

\begin{tabular}{|c|c|c|c|c|c|}
\hline \multirow{2}{*}{$\begin{array}{l}\text { Characteristic } \\
\text { Surgical characteristics }\end{array}$} & \multicolumn{2}{|c|}{ OCA $(n=35)$} & \multicolumn{2}{|c|}{ Standard wound suture $(n=34)$} & \multirow{2}{*}{$\frac{P \text { value }}{P_{\text {value* }}^{*}}$} \\
\hline & Mean \pm SD & Median (min, max) & Mean \pm SD & Median (min, max) & \\
\hline Time required for wound closure (seconds) [T] & $80.6 \pm 91.5$ & $45.0(30.0,480.0)$ & $344.6 \pm 171.2$ & $357.5(100.0,930.0)$ & $<0.001$ \\
\hline Length of wound $(\mathrm{mm})[\mathrm{L}]$ & $40.2 \pm 15.0$ & $40.0(15.0,69.0)$ & $34.8 \pm 13.6$ & $31.5(20.0,80.0)$ & 0.106 \\
\hline Mean length of wound closure per second $(L / T)$ & $0.78 \pm 0.45$ & $0.78(0.08,1.94)$ & $0.11 \pm 0.04$ & $0.10(0.06,0.23)$ & $<0.001$ \\
\hline \multicolumn{6}{|l|}{ Demographic characteristics } \\
\hline Continuous variables & Mean \pm SD & Median (min, max) & Mean \pm SD & Median (min, max) & $P$ value ${ }^{*}$ \\
\hline Age (years) & $38.9 \pm 12.5$ & $41.0(18,59)$ & $38.3 \pm 9.6$ & $39.5(20,56)$ & 0.871 \\
\hline Tumour size (cm) & $3.4 \pm 1.2$ & $3.5(1.3,6.0)$ & $3.3 \pm 1.4$ & $3.0(1.0,6.5)$ & 0.504 \\
\hline Categorical variables & \multicolumn{2}{|c|}{ No. (\%) of patients } & \multicolumn{2}{|c|}{ No. (\%) of patientsł } & $\mathrm{P}$ value $\dagger$ \\
\hline \multicolumn{6}{|l|}{ Co-morbidity } \\
\hline Good & \multicolumn{2}{|c|}{$23(65.7)$} & \multicolumn{2}{|c|}{$26(76.5)$} & 0.282 \\
\hline Diabetes & \multicolumn{2}{|c|}{0} & \multicolumn{2}{|c|}{$1(2.9)$} & \\
\hline Others & \multicolumn{2}{|c|}{$12(34.3)$} & \multicolumn{2}{|c|}{7 (20.6) } & \\
\hline \multicolumn{6}{|l|}{ Pathology } \\
\hline FA & \multicolumn{2}{|c|}{$18(51.4)$} & \multicolumn{2}{|c|}{$21(61.8)$} & 0.184 \\
\hline FCD & \multicolumn{2}{|c|}{$2(5.7)$} & \multicolumn{2}{|c|}{$5(14.7)$} & \\
\hline Others & \multicolumn{2}{|c|}{$15(42.9)$} & \multicolumn{2}{|c|}{$8(23.5)$} & \\
\hline \multicolumn{6}{|l|}{ Laterality } \\
\hline Left & \multicolumn{2}{|c|}{$17(48.6)$} & \multicolumn{2}{|c|}{$14(41.2)$} & 0.854 \\
\hline Right & \multicolumn{2}{|c|}{$16(45.7)$} & \multicolumn{2}{|c|}{$18(52.9)$} & \\
\hline Bilateral & \multicolumn{2}{|c|}{$2(5.7)$} & \multicolumn{2}{|c|}{$2(5.9)$} & \\
\hline \multicolumn{6}{|l|}{ Quadrant of lesion } \\
\hline Upper outer & \multicolumn{2}{|c|}{$12(34.3)$} & \multicolumn{2}{|c|}{$17(50.0)$} & 0.128 \\
\hline Upper inner & & (37.1) & & (23.5) & \\
\hline Lower outer & & (20.0) & & (5.9) & \\
\hline Lower inner & & (5.7) & & (17.6) & \\
\hline Others & & (2.9) & & (2.9) & \\
\hline Surgeon & & & & & \\
\hline Specialist & & $(77.1)$ & & $(64.7)$ & 0.428 \\
\hline Trainee under supervision & & (22.9) & & $(32.4)$ & \\
\hline
\end{tabular}

Abbreviations: FA = fibroadenoma; FCD = fibrocystic disease; OCA = octylcyanoacrylate tissue adhesive; $\mathrm{SD}=$ standard deviation

* Wilcoxon rank sum test

† Fisher's exact test

‡ Because of rounding, not all percentages total 100

Use of OCA was associated with significantly less time to complete the wound closure process compared with suture (mean, 80.6 seconds vs 344.6 seconds; $\mathrm{P}<0.001$; Table 1 ). With similar length of surgical wound, OCA required 7.1 times less time to close the wound than suture $(\mathrm{P}<0.001)$.

\section{Wound conditions in early postoperative period (day 0-1) and at first follow-up (day 10-14)}

The occurrence of adverse wound condition is shown in Table 2. There was no unfavourable condition noticed upon first-day follow-up. Wound complications on day 10-14 all occurred in the OCA group.

\section{Cosmetic grading by an evaluator and patients on day 30 and 180}

Table 3 summarises the incidence of any wound cosmetic problem on day 30 and 180 . Cosmetic problems were found only on day 30 , and were not confined to any one group. One patient from the suture group felt that the overall appearance of the surgical wound on day 30 was bad but subsequently 
TABLE 2. Breast cancer patients with wound complications after wound closure by either OCA $(n=35)$ or standard suture $(n=34)$ on early postoperative period (day $0-1)$ and upon first follow-up (day $10-14$ )

\begin{tabular}{|c|c|c|c|c|}
\hline Wound condition & Day $0-1$, No. $(\%)$ of patients & P value* & Day $10-14$, No. $(\%)$ of patients & P value* \\
\hline \multicolumn{5}{|l|}{ Wound infection } \\
\hline OCA & 0 & NA & $2(5.7)$ & 0.493 \\
\hline Suture & 0 & & 0 & \\
\hline \multicolumn{5}{|l|}{ Dehiscence } \\
\hline OCA & 0 & NA & $1(2.9)$ & 1.000 \\
\hline Suture & 0 & & 0 & \\
\hline \multicolumn{5}{|l|}{ Oozing } \\
\hline OCA & 0 & NA & $2(5.7)$ & 0.493 \\
\hline Suture & 0 & & 0 & \\
\hline \multicolumn{5}{|l|}{ Discharge } \\
\hline OCA & 0 & NA & $3(8.6)$ & 0.239 \\
\hline Suture & 0 & & 0 & \\
\hline
\end{tabular}

Abbreviations: NA = not applicable; OCA = octylcyanoacrylate tissue adhesive

* Fisher's exact test

TABLE 3. Breast cancer patients with cosmetic problems with surgical wound closure by either OCA $(n=35)$ or standard suture $(\mathrm{n}=34)$, graded by an evaluator on day 30 and day 180

\begin{tabular}{|c|c|c|c|c|}
\hline Wound cosmetic problem & Day 30, No. $(\%)$ of patients & P value* & Day 180, No. $(\%)$ of patients & P value* \\
\hline \multicolumn{5}{|l|}{ Step-off borders } \\
\hline OCA & $1(2.9)$ & 1 & 0 & NA \\
\hline Suture & 0 & & 0 & \\
\hline \multicolumn{5}{|l|}{ Contour irregularities } \\
\hline OCA & 0 & 0.239 & 0 & NA \\
\hline Suture & $2(5.7)$ & & 0 & \\
\hline \multicolumn{5}{|l|}{ Margin separation } \\
\hline OCA & $5(14.3)$ & 0.428 & 0 & NA \\
\hline Suture & $2(5.7)$ & & 0 & \\
\hline \multicolumn{5}{|l|}{ Edge inversion } \\
\hline OCA & $1(2.9)$ & 1 & 0 & NA \\
\hline Suture & 0 & & 0 & \\
\hline \multicolumn{5}{|l|}{ Excessive distortion } \\
\hline OCA & 0 & 1 & 0 & NA \\
\hline Suture & $1(2.9)$ & & 0 & \\
\hline
\end{tabular}

Abbreviations: NA = not applicable; OCA = octylcyanoacrylate tissue adhesive

* Fisher's exact test

TABLE 4. Cosmetic grading by breast cancer patients of wounds closed by either OCA or standard suture on day 30 and day 180

\begin{tabular}{lcccccc}
\hline Evaluation period & \multicolumn{2}{c}{ OCA } & \multicolumn{2}{c}{ Suture } & \multirow{2}{*}{ P value* $^{*}$} \\
\cline { 2 - 3 } \cline { 5 - 6 } & Mean \pm SD & Median $(\min$, max $)$ & & Mean \pm SD & Median (min, max) & \\
\hline Day 30 & $7.37 \pm 2.17$ & $8(1,10)$ & & $8.09 \pm 1.36$ & $8(5,10)$ & 0.243 \\
Day 180 & $7.65 \pm 2.10$ & $8(2,10)$ & & $8.13 \pm 1.67$ & $8.25(5,10)$ & 0.403 \\
\hline
\end{tabular}

Abbreviations: OCA = octylcyanoacrylate tissue adhesive; $\mathrm{SD}=$ standard deviation

* Wilcoxon rank sum test 
TABLE 5. Patient opinion of different kinds of surgical wound management 30 days following breast cancer surgery

\begin{tabular}{|c|c|c|c|c|c|c|}
\hline \multirow[t]{3}{*}{ Patient opinion } & \multicolumn{6}{|c|}{ No. $(\%)$ of patients* } \\
\hline & \multicolumn{3}{|c|}{ Pain } & \multicolumn{3}{|c|}{ Ease of caring } \\
\hline & OCA & Suture & $P$ valuet & OCA & Suture & $P$ value $†$ \\
\hline Very good & $12(35.3 \%)$ & $13(39.4 \%)$ & 0.564 & $21(61.8 \%)$ & $13(38.2 \%)$ & 0.137 \\
\hline Good & $13(38.2 \%)$ & $15(45.5 \%)$ & - & $5(14.7 \%)$ & $14(41.2 \%)$ & - \\
\hline Neutral & $3(8.8 \%)$ & $3(9.1 \%)$ & - & $3(8.8 \%)$ & 2 (5.9\%) & - \\
\hline Bad & $6(17.6 \%)$ & $2(6.1 \%)$ & - & $4(11.8 \%)$ & $4(11.8 \%)$ & - \\
\hline Very bad & 0 & 0 & - & $1(2.9 \%)$ & $1(2.9 \%)$ & - \\
\hline Unknown & 1 & 1 & - & 1 & 0 & - \\
\hline
\end{tabular}

Abbreviation: OCA = octylcyanoacrylate tissue adhesive

* Unknown cases were excluded in the calculation of percentages

+ Fisher's exact test

commented it was "good" on day 180. No bad comments were received from any patient who had undergone wound closure with OCA.

For the patient's view of cosmetic outcome, a higher score was given to wounds closed by sutures compared with OCA on both day 30 and 180, although the standard deviations were larger in the OCA group, and the differences were not statistically significant (Table 4). Higher scores were given on day 180 compared with day 30 in both groups.

\section{Patients' opinion of different kinds of wound management 30 days after surgery}

The actual number of hospital or clinic visits was recorded. Patients in the OCA group required fewer visits than those in the suture group (16 OCA vs 18 sutures, $1.19 \pm 2.66$ vs $2.50 \pm 4.57 ; \mathrm{P}=0.063)$. A higher percentage of patients in the OCA group felt "very good" on 'self-showering' (OCA vs suture, $66.7 \%$ vs $21.2 \% ; \mathrm{P}<0.001)$, 'frequency of hospital/clinic visits for wound cleansing' (OCA vs suture, $66.7 \%$ vs $25.0 \%$; $\mathrm{P}=0.001)$, and 'comfort level of wound dressing' (OCA vs suture, $58.8 \%$ vs $18.2 \%$; $\mathrm{P}=0.003$ ) [Table 5]. More patients in the suture group rated "good", instead of "very good" for these three categories. The same applied for 'ease of caring' although statistical significance was not reached. For patients who commented "bad" or "very bad", the percentages were generally higher from the OCA group. There was no significant difference between the two groups for reports about pain $(\mathrm{P}=0.564)$.

\section{Discussion}

Tissue adhesive material has long been used in wound closure in western countries, and offers the advantages of faster closure, need for less postoperative wound care, and higher patient satisfaction.
In this study among Chinese women, we demonstrated that time required for wound closure was much less in the OCA group compared with the SWS group $(\mathrm{P}<0.001)$. Although the difference was significant, time required for wound closure was not a significant concern for the surgeon.

There were three instances of postoperative complications in the OCA group. In two patients, the surgery was performed by a trainee under supervision, and in one by a specialist. One patient required secondary suturing 3 weeks later. The other two were treated conservatively with antibiotics. We postulate that there is a learning curve for closure with OCA, thus technical skill and experience of the surgeon may play a role.

For cosmetic outcome, the score was comparable in both groups, although slightly higher in the SWS group. Nonetheless, the difference was less than 1 point on a scale of 10 . The standard deviation in the OCA group was wider (OCA 2.17 vs SWS 1.36) at day 30 but was not statistically significant.

For wound problems, margin separation occurred on postoperative day 30 in five patients in the OCA group compared with two in the SWS group. There was no statistical difference in cosmetic problem grading between the two study groups. It should be noted that tissue adhesive wound repair is a manual skill, just like suturing, and requires practice and careful application. Factors such as wound oozing or discharge may hinder proper functioning of the tissue adhesive.

The skin of patients of Chinese or Asian descent is more prone to keloid scarring and pigmentation, thus the effect of using tissue adhesives may differ to that of a western population. A previous study did not show any difference in the rate of hypertrophic scar formation. ${ }^{10}$ In our study, there was no hypertrophic scar or keloid formation in either group. 
No. (\%) of patients

\begin{tabular}{|c|c|c|c|c|c|c|c|c|}
\hline \multicolumn{3}{|c|}{ Self-showering } & \multicolumn{3}{|c|}{$\begin{array}{c}\text { Frequency of hospital/clinic visits for wound } \\
\text { cleansing }\end{array}$} & \multicolumn{3}{|c|}{ Comfort level of wound dressing } \\
\hline OCA & Suture & P valuet & OCA & Suture & P valuet & OCA & Suture & $\mathbf{P}$ value \\
\hline $22(66.7 \%)$ & 7 (21.2\%) & $<0.001$ & $22(66.7 \%)$ & $8(25.0 \%)$ & 0.001 & 20 (58.8\%) & $6(18.2 \%)$ & 0.003 \\
\hline $3(9.1 \%)$ & $14(42.4 \%)$ & - & $4(12.1 \%)$ & $17(53.1 \%)$ & - & $6(17.6 \%)$ & $16(48.5 \%)$ & - \\
\hline $6(18.2 \%)$ & $10(30.3 \%)$ & - & $4(12.1 \%)$ & $4(12.5 \%)$ & - & $4(11.8 \%)$ & 7 (21.2\%) & - \\
\hline $2(6.1 \%)$ & $1(3.0 \%)$ & - & $2(6.1 \%)$ & $1(3.1 \%)$ & - & $4(11.8 \%)$ & $3(9.1 \%)$ & - \\
\hline 0 & $1(3.0 \%)$ & - & $1(3.0 \%)$ & $2(6.3 \%)$ & - & 0 & $1(3.0 \%)$ & - \\
\hline 2 & 1 & - & 2 & 2 & - & 1 & 1 & - \\
\hline
\end{tabular}

There was a significant difference in preference in terms of self-showering, frequency of hospital/ clinic visits, and comfort level of dressing between OCA and SWS groups. These factors affect patients since they impact on daily activities and saving of time. On the other hand, there was no statistical difference in degree of pain, although the Phi value was very small, thus a larger sample size may be required to detect any difference. The sample size for all other values was adequate.

In terms of cost, a study in Hong Kong has shown that tissue adhesive is more expensive than SWS ${ }^{11}$ but may be more cost-effective from a social viewpoint in terms of superior cosmetic outcome and overall patient satisfaction.

\section{Strengths and weaknesses of this study}

First, this was a prospective randomised study confined to closure of benign breast lump wounds and thus not necessarily applicable to all surgical wounds. We did not determine the number of eligible patients for the study, or note how many of them refused to take part. This may have led to selfselection bias. Second, the operation was performed by different surgeons of different seniority, and may have led to varying levels of surgical technique. This was not shown to be statistically significant but the sample size was not designed to reflect this. Lastly, during wound evaluation, the surgeon might not have been totally blind to the type of closure if sutures or stitch marks were visible. This may be a cause of blinding bias. The use of a scoring scale is also a subjective evaluation, and may be influenced by the patient's mood and other factors.

\section{Conclusions}

The use of OCA should be discussed and offered to patients as an option for wound closure in breast surgery. It achieves faster wound closure, is not inferior to standard wound closure, has a higher comfort level, and requires less frequent clinic visits. Understanding cost-effectiveness is essential in medical care, thus OCA should be offered as an public sector where it is now widely available.

\section{Acknowledgements}

We thank Mr Jack Chau and Miss Fidelia Wong for performing the early statistical analysis, and $\mathrm{Mr}$ Ling-hiu Fung and Mr Wing-pan Luk of the Hong Kong Sanatorium \& Hospital for the later review and re-running of the statistical analysis methods. We also thank Ethicon, Johnson and Johnson Company for providing the OCA study material.

\section{Declaration}

Johnson and Johnson provided the study material. No other conflict of interests was declared by authors.

\section{References}

1. Top ten cancers in 2013. Hong Kong Cancer Registry. Available from: http://www3.ha.org.hk/cancereg/statistics. html. Accessed Jan 2016.

2. Singer AJ, Quinn JV, Clark RE, Hollander JE; TraumaSeal Study Group. Closure of lacerations and incisions with octylcyanoacrylate: a multicenter randomized controlled trial. Surgery 2002;131:270-6.

3. Chow A, Marshall H, Zacharakis E, Paraskeva P, Purkayastha S. Use of tissue glue for surgical incision closure: a systematic review and meta-analysis of randomized controlled trials. J Am Coll Surg 2010;211:11425.

4. Maw JL, Quinn JV, Wells GA, et al. A prospective comparison of octylcyanoacrylate tissue adhesive and suture for the closure of head and neck incisions. J Otolaryngol 1997;26:26-30. option to be provided as a self-financed item in the 
5. Toriumi DM, O'Grady K, Desai D, Bagal A. Use of octyl-2cyanoacrylate for skin closure in facial plastic surgery. Plast Reconstr Surg 1998;102:2209-19.

6. Gennari R, Rotmensz N, Ballardini B, et al. A prospective, randomized, controlled clinical trial of tissue adhesive (2-octylcyanoacrylate) versus standard wound closure in breast surgery. Surgery 2004;136:593-9.

7. Nipshagen MD, Hage JJ, Beekman WH. Use of 2-octylcyanoacrylate skin adhesive (Dermabond) for wound closure following reduction mammaplasty: a prospective, randomized intervention study. Plast Reconstr Surg 2008;122:10-8.

8. Quinn JV, Osmond MH, Yurack JA, Moir PJ. N-2butylcyanoacrylate: risk of bacterial contamination with an appraisal of its antimicrobial effects. J Emerg Med
1995; 13:581-5.

9. Soni A, Narula R, Kumar A, Parmar M, Sahore M, Chandel M. Comparing cyanoacrylate tissue adhesive and conventional subcuticular skin sutures for maxillofacial incisions-a prospective randomized trial considering closure time, wound morbidity, and cosmetic outcome. J Oral Maxillofac Surg 2013;71:2152.e1-8.

10. Wilson AD, Mercer N. Dermabond tissue adhesive versus Steri-Strips in unilateral cleft lip repair: an audit of infection and hypertrophic scar rates. Cleft Palate Craniofac J 2008;45:614-9.

11. Wong EM, Rainer TH, Ng YC, Chan MS, Lopez V. Costeffectiveness of Dermabond versus sutures for lacerated wound closure: a randomised controlled trial. Hong Kong Med J 2011;17 Suppl 6:4-8. 